\title{
Reflections on the Concept of Operator Workload
}

\author{
Rasmussen, Jens
}

Published in:

Proceedings of the Mental Workload. Its Theory and Measurement

Publication date:

1979

Document Version

Publisher's PDF, also known as Version of record

Link back to DTU Orbit

Citation (APA):

Rasmussen, J. (1979). Reflections on the Concept of Operator Workload. In Proceedings of the Mental Workload. Its Theory and Measurement (pp. 29-40). Plenum Publishing Corporation.

\section{General rights}

Copyright and moral rights for the publications made accessible in the public portal are retained by the authors and/or other copyright owners and it is a condition of accessing publications that users recognise and abide by the legal requirements associated with these rights.

- Users may download and print one copy of any publication from the public portal for the purpose of private study or research.

- You may not further distribute the material or use it for any profit-making activity or commercial gain

- You may freely distribute the URL identifying the publication in the public portal

If you believe that this document breaches copyright please contact us providing details, and we will remove access to the work immediately and investigate your claim. 


\section{REFLECTIONS ON THE CONCEPT OF OPERATOR WORKLOAD 1}

Jens Rasmussen

Risø National Laboratory

Denmark.

In the context of our research at Ris@ on the data processing functions of human operators in automated, modern process plants, the concept of operator work load seems to be a rather qualitative, ambiguous characteristic of a work situation rather than a measure of the amount of work implied in a task.

Also, recent reviews of problems in the context of "Measurement of Man at Work" (Singleton, ed., 1971) suggest an increase in the diversity of measures and ambiguity of concepts following from a shift of emphasis from manual skill to data processing and decision making as the result of automation and computerization of technical systems.

This shows that the time has come to break away from the present analogies to physical work and to develop new descriptions of man's functions in automated systems; i.e., "we need to develop a philosophy of man-machine systems" (Singleton, 1971, p.58) to serve as an explicit frame of reference for meaningful measures of work performance.

There is a tendency to extrapolate from analytical, quantitative models developed for manual skills and sensory-motor responses in vehicle control into the field of supervisory control independently of a simultaneous development of models of human data processing within the fields of artificial intelligence, robotics, and linguistic research. A new philosophy of man-machine systems should be a frame of reference which allows research to draw upon the results from all these different approaches which place emphasis on different human abilities.

The different meanings of "mental work load" in our context are very well formulated by the "Webster" interpretations of the word "load".

From "load" as "an item .... carried"; "a .... weight supported by something", Webster associates to "something that weighs down the mind or spirit", a very precise

${ }^{1}$ MENTAL WORKLOXD Fditcd bv Neville Moray (Plenum Publishing Corporation, 1979) 
formulation of the emotional quality of work which directly influences the amount of effort that an operator can or is willing to spend.

"External resistance overcome by machine or prime mover" leads to "the amount of work that a person carries or is expected to carry" which are quantitative statements referring to the demands placed on man by the environment. These interpretations are appropriate as long as the capacity problem is related to the human motor system, i.e. his physical power. The introduction of communication systems, such as railways and telephone exchanges creates the same problem for Webster as our human data processor does for us, and the solution is: load is "the demand upon the operating resources of a system".

However, even this definition is useful only as a measure of work load in onedimensional demand/resource systems. In general, a demand/resource relation is multidimensional and the different measures must be used to characterize the global "load". The different aspects of human resources in a complex mental task are not independent; the actual capacities of different mental resources are interconnected and the overall "load" cannot be evaluated unless a description or model of the operator's mental processes in available.

\section{STRESS AND STRAIN}

Stress and strain are supposed to indicate the effects of work load upon man, and again there seems to be a sim-ple-transfer from the loading of physical structures through manual work and physiology to mental activities. As with the term "load", however, the concepts become ambiguous in this context. Mental work load does change man's mental 'shape' in terms of the resources he makes available. The relation, however, is complex and the source of much debate. It is not even monotone; if load increases the resources we call the effect "motivation"; if the opposite is the case we talk about "stress". Physiological variables change with mental activity, but the different measures tend to be divergent and the calibration of measures is typically not stable with time (Wisner, 1971). Physiological measures seem to be suited mostly as indicators of changes in mental work demand.

To conclude, in the context of monitoring and supervisory tasks of the operator in automated plants, the concept of work load is mainly useful as a measure of the degree to which work demands "weigb down the mind or spirits" of the operator; i.e. of the subjective quality of work situations, and stress as an indication of the resulting emotional state of the operator. The question of the fit between amount and context of work demand and operator resources must be evaluated within a much more re- 
fined framework.

\section{DEMANDS AND RESOURCES; MEASURES AND MODELS}

The work situation of a human supervisor in automated plants has several characteristic features.

He has a large variety of tasks related to a system which he comes to know very intimately. What he learns from one task will be used in others and his performance in different tasks cannot be described in isolation. Furthermore, the operator will use several mental mechanisms which have basically different limiting properties and which are most adequately described by different types of models. A "morphology of models" is therefore needed to interrelate the different measures derived from different types of models and to define the limitations of use of the models.

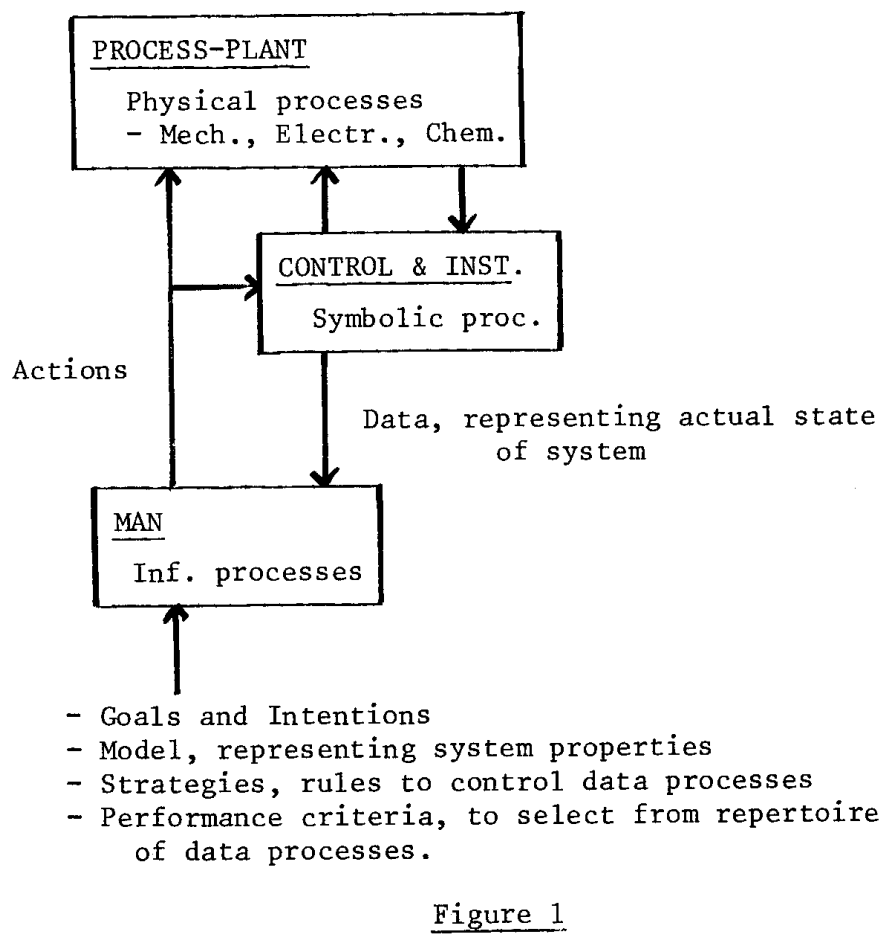

Another characteristic of the operator's situation as a supervisor are the demands arising from unfamiliar, infrequent situations - he is a diagnostician and a decision maker. Models as well as measures must therefore cover not only the average performance in frequent tasks but also his response in special, infrequent tasks, which very likely can be related to events implying high risks. 
The system we are considering is shown in Fig. 1. A man supervises an automated system. He monitors the information from the system to see if he recognizes the situation as normal or acceptable. This may very well be a one dimensional demand problem and the fractional time spent on reading instruments will then indicate how near he is to the limits of his resources (Senders, 1970). However, if he detects a need to intervene with the system, he has to identify the actual state of the system, decide on the proper corrective task and to perform the manual actions. Now, in this case, the man has a complex data processing task, and it is as inappropriate to discuss his mental load without referring to his mental equipment and strategies as it is meaningless to discuss physical load in a manual task without referring to the power tools used.

In general, a data processing system will be a multi-dimensional demand/resource system. The flexibility of such a system very often makes it possible to solve a demand/resource conflict along one of the dimensions by a change in strategy or type of process (Bruner et al., 1956, Rasmussen and Jensen, 1974).

Some dimensions of the human resource system in data processing typically are:

- the time allowed for the task, when paced by the system;

- the amount of input information available or the cost of observations;

- the a priori information on system structure and function or useful analogies (mental models);

- the capacity of short term memory;

- the capacity of the mental processes used (sensory motor or cognitive);

- the code, level of abstraction, used in processing;

- the repertoire of ready-made-solutions - i.e. experience and skill;

- the risk, the cost of mistakes.

Demand/resource conflicts in one dimension can be solved by spare capacity in another: lack of input information can be compensated by use of a more complex mental model; capacity problems by recoding and "chunking" information to a higher level of abstraction, etc. -

It is general practice as a last resort to let the operator take over pacing from the system. In crowded air traffic, controllers may "stack" aircraft in waiting positions; in process control, "set back" to safe operating condition is used. 


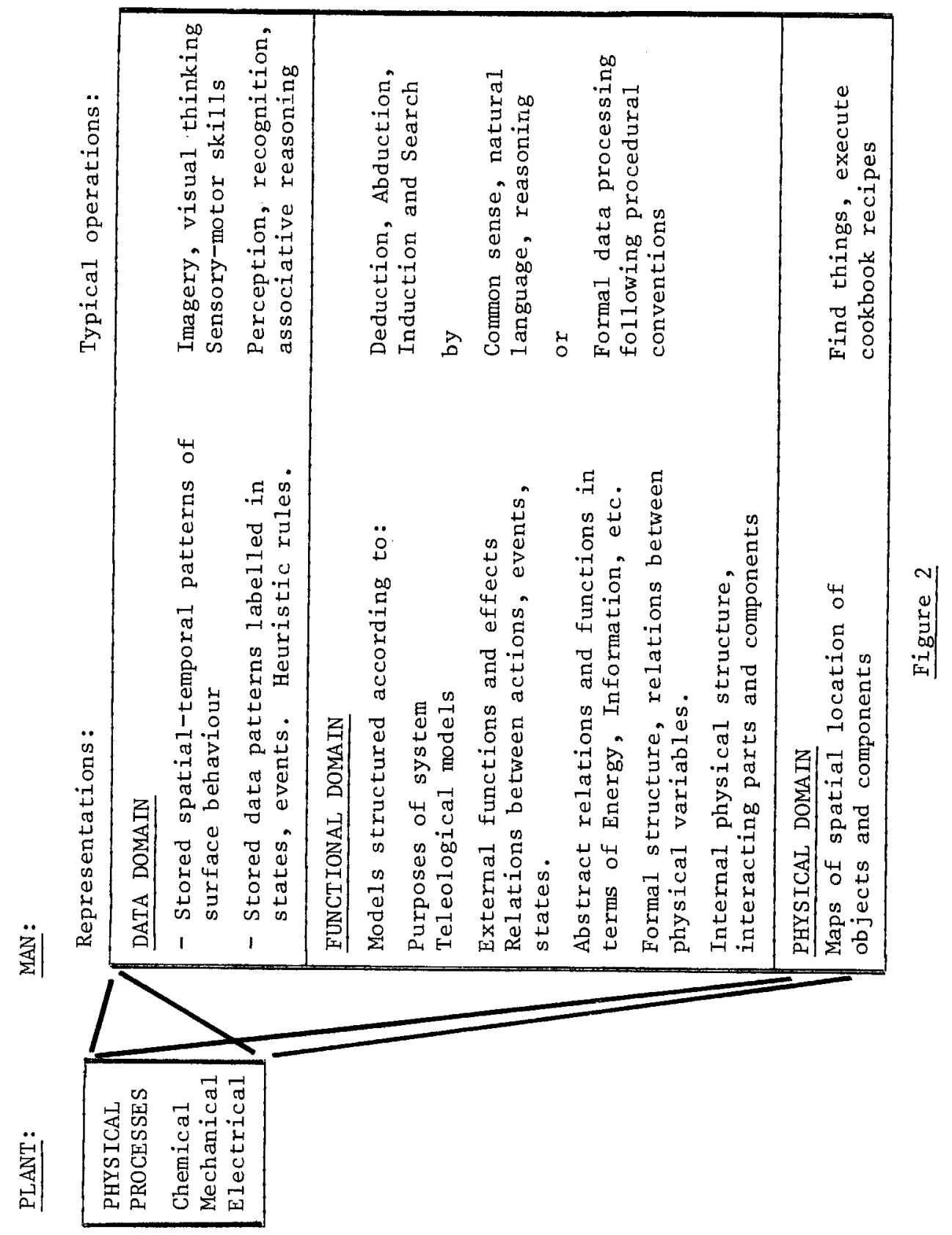




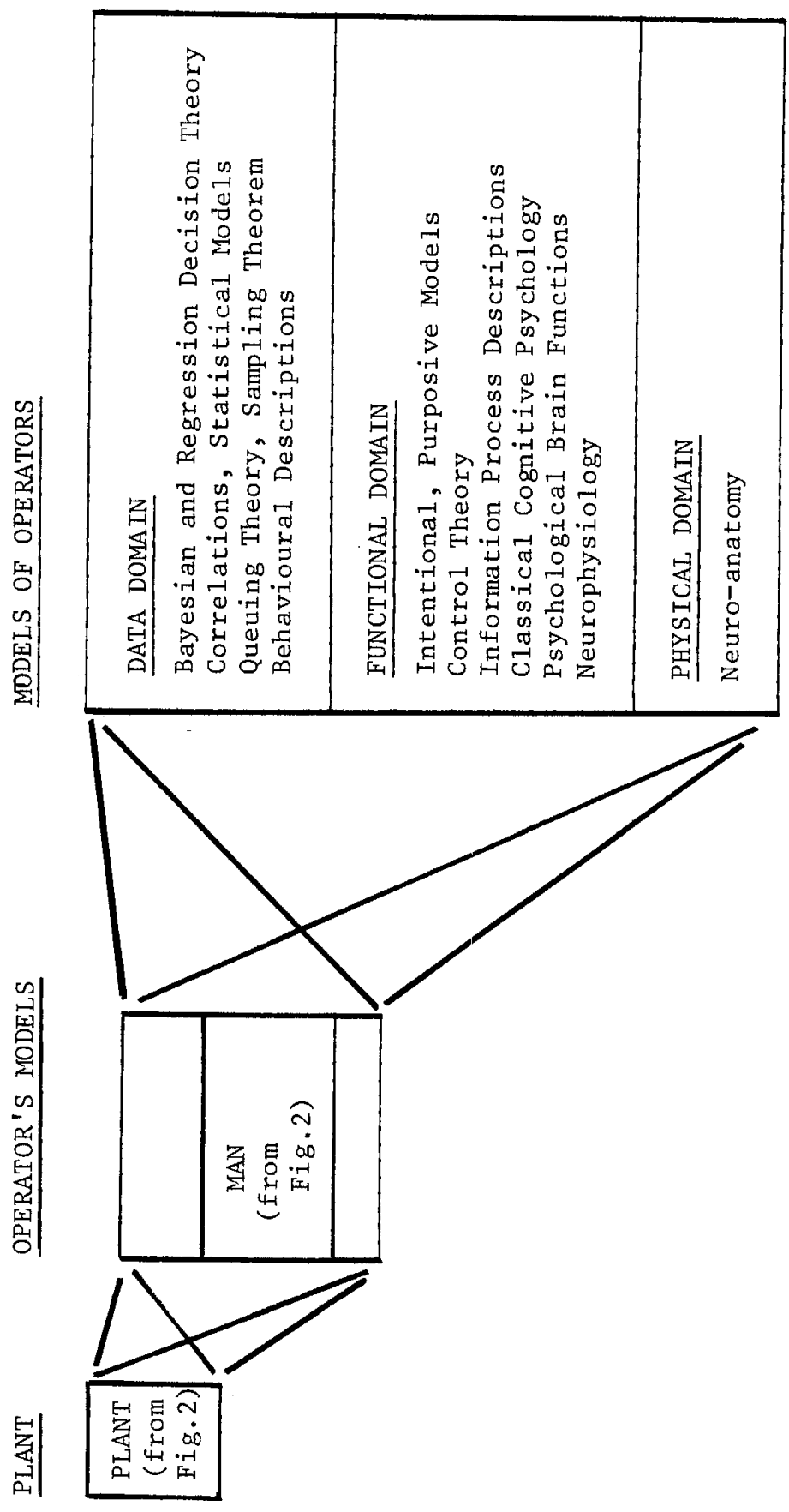

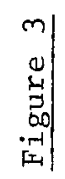


Taken as a global measure of the extent to which a given task loads the operating resources of a human operator, work load turns out to be a measure characterizing a specific man-machine encounter. a situation not the task itself.

The data processing task can be considered as a recoding of input information into a problem space and a search guided by a representation (mental model) of the properties of the environment. A major problem in the present context is the great flexibility of human data processors which is due to the availability of different categories of mental models and consequently different sets of limiting properties of the related data processes.

Such categories are illustrated by Fig.2, and discussed elsewhere in more detail. The point in the present context is that, depending upon model category, the strategies will be tightly connected to specific task or system properties. This means that the adaptation to changes in system conditions or task which is a typical aspect of a monitoring and supervisory task, can imply a switch-over to another category of models and strategies. A key question in any case is: How sensitive is the demand/resource relation along the different axes to changes in task or system? And which transformation is needed to map changes in the environment onto changes in the characteristics of the problem space and strategies? How is this relationship described? We are now in the complex situation of Fig.3, with an obser-@er having several levels for representing the operator's representation of his environment. And we have to face this complexity in order to discuss preferences for a priori or empirical measures versus systems and models for prediction of man-machine system performance.

In supervisory control of automated process plants, man acts as an adaptive, selforganizing and goal oriented data processor and therefore attempts to predict his performance lead to several problems resulting from his great flexibility. At present we find the major problem that of establishing the necessary categories of models, of defining their interrelation and their relation to basic human mechanism with their various limiting properties rather than to find quantitative measures of human performance.

The effectiveness of the human data processor is due to the availability of a large repertoire of data subroutines. They are of basically different categories with respect to process type and limiting properties, and are conveniently modelled within different frameworks. Very frequent and repetitive functions are served by a kind of high capacity parallel processing which is holistic, i.e. not decomposable into separable 
subfunctions. This is the case for manual skill where attention, perception and complex movements are controlled by an internal, dynamic world model, etc. This category of functions is typically modelled within the framework of control theory and information theory (Curry, Moray, Senders, Sheridan, in: Sheridan and Johannsen, 1976).

In less familiar situations the data processes have the character of associative chaining of events, states, actions, i.e. processes which are typically described by decision theory (Slovic et al., 1973), fuzzy set theory (Zadeh et al., 1975), semantic networks (Rieger, 1976, Schank, 1975).

In unique, new situations, the processes turn into genuine problem solving based on formal operations such as deduction and a search in problem space. Such processes have been modelled in detail within artificial intelligence (Newell and Simon, 1972).

The problem in modelling real life situations is that all of these process types are involved and they cannot be studied in isolation. We need to know how the basic human mental mechanisms and their limiting properties are reflected in the different process models and how the models are interrelated. For instarce, is there any connection through a basic human mechanism between the features of the temporal-spatial internal model behind attention and manual skill and the systematic bias due to if representativeness" in intuitive judgements found by Tversky and Kahnemann (1974)?

Can the concepts of models, data and strategies be formalized in a stringent way and used to interrelate the different categories of process descriptions? In practice, we do not need to predict the data processes of an operator in detail. As far as we can predict the type of model, data and strategy he will use in a specific task, we will be able to support him by proper design of interface.

Being an adaptive data processor, the complexity of man's behaviour "will reflect characteristics largely of the outer environment" (Simon, 1969, p.25). This means that a model of supervisory man cannot be developed by adding together models of different subroutines found separately from selective experiments. A model of supervisory man must be determined from analysis of real life performance. At present we see no other method than a structure and process analysis of verbal protocols and conversations. This is, however, a time consuming task and good protocols are difficult to obtain. Hopefully, a more stringent frame of reference for the different categories of human data processes and mental mechanisms and a clever use of 
the recording facilities in modern interactive computer control systems will make this research more efficient.

Simon continues in the light of the current goal". This is obvious, but far from trivial. First of all, research on real life strategies must be based on an intimate knowledge of the functional properties of the system supervised and its demands upon the operator. The initial goal of finding the cause of an event can develop into locating a change in the data domain (for immediate association to counteraction); in the functional domain (to plan a compensating action) or in the physical domain (to repair or readjust the initial cause). Even when the system's actual demand is well specified, there will be great freedom for a subjective formulation of the "current goal" and of the performance criteria used for trade-offs among the demand/resource dimensions. This makes the individual task sequence vary depending upon persoir-and situation-related details. It also makes higher level analysis in terms of formal strategies - based on consistent sets of models, data and process rules - and heuristic rules for leaps between them attractive.

One thing still remains to be considered, the emotional aspect. How much effort can or is the operator willing to spend upon a specific task? This relates to the short-term emotional load from a work situation like motivation and stress, but also to the long term aspect such as attitudes, acceptance and beliefs which becomes more and more important as systems are designed for complex interactive data processing or man-computer cooperation (Halpin, et al., 1973). Research in this field is extremely important, but again in supervisory tasks we do not find the key problem to be one of measures and quantification, but rather to be related to definition and identification of categories: which

are the characteristics of work situations resulting in positive attitudes?

\section{CONCLUSION}

These general characteristics set the stage for the concluding remarks:

In future complex systems, man will typically be allocated functions as a monitor and supervisor. Models of his performance must itot only be able to predict his average response in frequent situations, but also his response in unique, infrequent tasks.

$\mathrm{He}$ is a highly adaptive and goal-oriented information processor. Models of his 
performance in well adapted situations are mainly models of his environment. Models of his performance must also reflect the limiting properties of his internal mechanisms.

The overall quality of human performance in a monitoring and supervisory task is typically measured by his reliability i.e. the probability that a change or fault in the system is met by an appropriate action - or by the time it will take him to restore normal operation. The effect of random human errors can only be predicted from statistical models based on empirical fault data (Swain, 1976). The effect of system properties must be considered in at least three independent ways:

- The efficiency with which the interface activates the appropriate intention or goal within the operator. Which information is used to update his internal model, to direct his attention and activate his value system?

- The freedom given the operator to develop and use a repertoire of data processing which allows efficient trade-offs in resource/demand conflicts. This freedom strongly depends upon the selection, precondition, coding and formatting of the information presented to him. This must not be judged from the viewpoint of rational, formal choices, but from the performance criteria in actual use, e.g. like the "law of least resistance".

- The extent to which the operator will be willing to or can use his normal resources and the resources offered by the system without his performance being impaired by negative attitudes, stress or distrust.

In general, these qualities cannot be quantified or measured; the attributes of an optimal system design cannot even be defined qualitatively. Question: Will today's research add up to an integrated view of the process operator or are we using shotguns?

We cannot predict operator performance in general in the complex systems we design. However, we may be forced to design systems in which we can predict the performance of operators, at least in safety related tasks. Question: Which are the attributes of a task for which we today are able to predict the performance quantitatively? 


\section{REFERENCES}

Bruner, J.S., Goodnow, J.J. and Austin, G.A. "A Study of Thinking", Wiley, New York, 1956.

Halpin, S.M., Johnson, E.M. and Thornberry, J.A. "Cognitive Reliability in Manned Systems". IEEE Transactions on Reliabilitv. Vol. R-22, No.3, August 1973.

Newell, A. and Simon, H.A. "Human Problem Solving", Prentice-Hall, 1972.

Rasmussen, J. and Jensen, A. "Mental Procedures in Real Life Tasks": A Case Study of Electronic Trouble Shooting", Ergonomics, 17, No.3, p. 293-307, 1974.

Rieger, C. "An Organization of Knowledge for Problem Solving and Language Comprehension". Artificial Intelligence $\underline{7}$ (1976), p. 89-127.

Schank, R.C. "Conceptual Information Processing", North-Holland Publishing Company, Amsterdam, Oxford, 1975.

Senders, J.W. "The Estimation of Operator Workload in Complex Systems", in Systems Psvcholo, K.B. DeGreene (Ed.), McGraw-Hill, 1970

Sheridan, T.B. and Johannsen, G. (Ed.) "Monitoring Behavior and Supervisory Control Plenum Press,-New York and London, 1976.

Simon, H.A. "The Sciences of the Artificial" M.I.T. Press, 1969.

Singleton, W.T. (Ed.) 11 Measurement of Man in Work; Taylor and Francis Ltd., London, 1971.

Slovic, P. and Lichtenstein, S. "Comparison of Bayesian and Regression Approaches to the Study of Information Processing in Judgement", in L. Rappoport and D.A. Summers (Eds.): Human Judgement and Social Interaction, 1973, Holt,

Swain, A.D. "Sandia Human Factors Program for Weapon Development", Sandia Laboratories SAND 76-0327, June 1976.

Tversky, A. and Kahneman, D. "Judgement under Uncertainty: Heuristics and Biases", Science, 185, 1124-1131, 1974.

Wisner, A. "Electrophysiological Measures for Tasks of Low Energy Expenditure". in "Measurement of Man at Workl', Singleton (Ed.), Taylor and Francis, London, 1971.

Zadeh, L.A. et al. (Eds.) "Fuzzy Sets and Their Al)plications to Cognitive and Decision Processes". Academic Press, New York, 1975. 